\title{
Efeitos do Ensino do Ecoico Aliado a Repertórios Básicos de Leitura sobre a Nomeação de Palavras em Crianças com Deficiência Intelectual
}

\author{
Máyra Laís de Carvalho Gomes ${ }^{1}$ \\ Priscila Benitez \\ Universidade Federal de São Carlos, São Carlos, SP, Brasil \\ Camila Domeniconi \\ Departamento de Psicologia da Universidade Federal de São Carlos, São Carlos, SP, Brasil \\ Ana Claudia Moreira Almeida Verdu \\ Universidade Estadual Paulista, Bauru, SP, Brasil
}

\begin{abstract}
Resumo
Os repertórios discriminativos básicos podem ser considerados importantes pré-requisitos para a aquisição da leitura. O presente trabalho verificou a influência do ensino gradual de repertórios discriminativos prévios ao repertório de leitura sobre a aquisição desta habilidade para crianças com deficiência intelectual, destacando o ensino de ecoico aliado à nomeação de figuras. Participaram duas crianças com Síndrome de Down e deficiência intelectual, com dificuldades para oralizar. Foram ensinadas relações entre estímulos baseadas em seleção de figuras e palavras impressas mediante palavra ditada; e entre estímulos e respostas como ecoar conforme palavra ditada, nomear figuras e construir palavra impressa. Após este ensino foram testadas a nomeação das palavras impressas e as relações de equivalência entre palavra impressa e figura e vice versa. Os desempenhos nas tarefas relacionais emergentes passaram de $45 \%$ de acertos, em média, avaliados no pré-teste, para a média de $77 \%$ de acertos no pós-teste. Os participantes que antes apresentavam repertório nulo de nomeação passaram a ler. O ensino de ecoico pôde auxiliar na nomeação mais precisa de palavras impressas e o planejamento gradual do ensino de habilidades relacionais básicas de nomeação proporcionou a ampliação deste repertório.
\end{abstract}

Palavras-chave: Nomeação de palavras, relações de equivalência, ecoico, deficiência intelectual.

\section{Effects of Echoic Teaching Combined with Basic Reading Repertoires on Word Naming in Children with Intellectual Disabilities}

\begin{abstract}
The basic discriminative repertoires may be considered important prerequisite for reading acquisition. This study investigated the influence of the gradual teaching of discriminative repertoires prior to reading on the acquisition of this skill in children with intellectual disabilities, emphasizing the echoic teaching combined with figure naming. Participants were two children with Down syndrome and intellectual

Endereço para correspondência: Rua Amazonas, nº 2534, Marques, Teresina, PI, Brasil 64003-170. E-mail: mayra.lais@hotmail.com, pribenitez@yahoo.com.br, camila@ufscar.br e anaclaudiaverdu@gmail.com Financiamento: Bolsa de Mestrado e Doutorado Coordenação de Aperfeiçoamento de Pessoal de Nível Superior (CAPES).

Todas as autoras integram o Instituto Nacional de Ciência e Tecnologia - Comportamento, Cognição e Ensino (INCT-ECCE), coordenado pela Dra. Deisy G. De Souza, com financiamento do CNPq (processo\# 573972/2008-7) e da FAPESP, (processo\# 2008/ 57705-8).
\end{abstract}


disabilities, with difficulties in vocalization. Relationships between stimuli were taught based on the selection of figures and printed words when presented with dictated words; and between stimuli and responses, such as echoing according to the dictated word, picture naming and constructing the printed word. After this teaching procedure, the naming of printed words and the equivalence relations between printed word and picture and vice versa were tested. Their performances in the emerging relational tasks increased from a mean of $45 \%$ correct evaluated in the pre-test to the mean of $77 \%$ correct in the posttest. Participants who had previously null repertoires of word naming started reading. Echoic teaching could assist in more accurate naming of printed words and the gradual teaching of basic relational skills of naming provided the expansion of this repertoire.

Keywords: Word naming, Equivalence relations, echoic, intellectual disability.

\section{Efectos de la Enseñanza del Ecoico Asociada a Repertorios Básicos de Lectura sobre el Nombramiento de Palabras en Niños con Discapacidad Intellectual}

\section{Resumen}

Los repertorios discriminativos básicos pueden ser considerados importantes requisitos para la adquisición de la lectura. Este estudio investigó la influencia de la enseñanza gradual de repertorios discriminativos previos al repertorio de lectura sobre la adquisición de esta habilidad para niños con discapacidad intelectual, destacando la enseñanza de ecoicos asociada al nombramiento de imágenes. Participaron dos niños con Síndrome de Down y discapacidad intelectual, con dificultades para oralizar. Se les enseñaron relaciones entre estímulos basadas en selección de imágenes y palabras mediante palabra dictada; y entre estímulos y respuestas como hacer eco según la palabra dictada, nombrar imágenes y construir palabra impresa. Terminada la etapa de enseñanza, se pusieron a prueba el nombramiento de las palabras impresas y las relaciones de equivalencia entre palabra impresa e imagen y viceversa. Los desempeños en tareas relacionales emergentes aumentaron de $45 \%$ de aciertos, en media, evaluados en la prueba previa, a la media de $77 \%$ de aciertos en el post-test. Los participantes que presentaban repertorio nulo de nombramiento empezaron a leer. La enseñanza de ecoicos puede contribuir para el nombramiento más preciso de palabras impresas y la planificación gradual de la enseñanza de habilidades relacionales básicas de nombramiento proporcionó la expansión de este repertorio.

Palabras clave: Nombramiento de palabras, relaciones de equivalencia, ecoico, discapacidad intelectual.

De acordo com de Rose (1993), o ato de ler pode ser decomposto em repertórios menores, descrito por relações entre estímulos e entre estímulos e respostas, e serem relacionados por classes de equivalência, formando, assim, uma rede de relações: algumas diretamente ensinadas e outras relações emergentes desse ensino. O paradigma de equivalência de estímulos descreve as condições sob as quais estímulos passam a formar classes de equivalência. Os critérios operacionais partem dos pressupostos de substitutabilidade entre estímulos formalmente diferentes (de Rose \& Bortoloti, 2007; Sidman, 1994; Sidman \& Tailby, 1982).
As relações de equivalência são identificadas quando as relações entre membros de uma classe de estímulos demonstram as três propriedades formais definidoras de equivalência: reflexividade, simetria e transitividade (Sidman \& Tailby, 1982; Sidman, Wynne, Maguire, \& Barnes, 1989). Assim,

as propriedades reflexivas são aquelas que se mantêm entre um termo e ele mesmo (p. ex., $\mathrm{A}=\mathrm{A}$ ); as propriedades simétricas são aquelas em que a ordem dos termos é reversível (p. ex., se $\mathrm{A}=\mathrm{B}$, então $\mathrm{B}=\mathrm{A}$ ); e as propriedades transitivas são aquelas em que os termos comuns em dois pares ordenados 
determinam um terceiro par ordenado ( $\mathrm{p}$. ex., se $\mathrm{A}=\mathrm{B}$ e $\mathrm{B}=\mathrm{C}$, então $\mathrm{A}=\mathrm{C})$. (Catania, 1999, p. 166)

Dentre as muitas possibilidades de investigação, esse paradigma pode ser adotado no estudo de comportamentos de leitura, tais como: emitir uma resposta verbal diante de uma palavra impressa (comportamento textual que também pode ser denominado de decodificação ou de nomeação de palavra impressa) e o comportamento de ler com compreensão (comportamento, por exemplo, de relacionar figuras e palavras impressas e vice-versa). O mesmo estímulo textual é condição tanto para a emissão de uma resposta verbal quanto para a seleção de uma figura; e diferentes procedimentos de ensino, como os que envolvem o estabelecimento da rede de relações de equivalência, podem ser planejados na tentativa de garantir a aprendizagem de habilidades básicas e prévias à nomeação de palavras, a fim de facilitar a sua posterior aquisição.

A rede de relações de equivalência pode ser estabelecida por meio de discriminações condicionais, em que um estímulo modelo funciona como uma ocasião para a escolha de um dos estímulos de comparação. Algumas tarefas relacionais compõem a rede de relações envolvidas na nomeação de uma palavra impressa. São as tarefas de identidade entre figura-figura (BB) e entre palavra impressa-palavra impressa (CC), as de nomeação de figuras (BD), as de seleção auditivo-visual tais como entre palavra ditada-figura $(\mathrm{AB})$ e entre palavra ditada-palavra impressa (AC), as de seleção visual-visual como entre figura-palavra impressa (BC) e entre palavra impressa-figura (CB), as de cópia por composição de unidades menores (CE) e por manuscrito $(\mathrm{CF})$ e as de ditado por composição de unidades menores (AE) e por manuscrito (AF). De maneira simples, se um falante e ouvinte competente seleciona uma figura frente a uma palavra impressa (CB) e nomeia essa figura (BD), facilmente demonstrará a nomeação de palavras (CD), pois o controle exercido pelo estímulo figura (B) sobre a resposta verbal (D) será transferido para a palavra impressa (C). Outras relações podem oferecer elementos adicionais para o estabelecimento ou transferência de controle de estímulos. Por exemplo, para que a nomeação emerja, seja de palavras impressas, seja de figuras, ecoar palavras ditadas $(\mathrm{AD})$ é um pré-requisito importante.

A vantagem do uso da rede de relações como forma de compreender e ensinar o comportamento de ler está baseada na possibilidade de decompor tarefas complexas em tarefas mais simples, facilitando o processo de avaliação e de ensino-aprendizagem do repertório de nomeação (e.g. Fonseca, 1997; Melchiori, de Souza, \& de Rose, 2000). Essa forma de avaliação e de ensino de repertórios básicos para a leitura tem sido adotada com participantes com diferentes necessidades educacionais especiais como deficiência auditiva e uso de sistema de frequência modulada (Bevilacqua \& Souza, 2012), surdos que se comunicam em LIBRAS (Pereira \& Almeida-Verdu, 2012), com deficiência auditiva e implante coclear (Santos, 2012) e deficiência visual (Quinteiro, 2014), demonstrando quais as relações que já estão bem estabelecidas e quais deveriam ser alvo de ensino nesses aprendizes.

Os processos mais simples e as habilidades precursoras da aprendizagem de um novo repertório são considerados por Sidman (1977) como pré-requisitos importantes para a aquisição de nomeação. Eventuais fracassos na aprendizagem dos indivíduos devem ser atribuídos à inadequação dos procedimentos e não a características intrínsecas do aluno ou do meio do qual provém (de Rose, 2005). O modelo das relações de equivalência tem delineado procedimentos e estruturas de ensino com capacidade demonstrada de manejar algumas das dificuldades do processo de aprendizagem (e.g. de Rose, de Souza, Rossito, \& de Rose, 1989; de Souza \& de Rose, 2006; Sidman, 1994; Stromer, Mackay, \& Stoddard, 1992). Um programa de ensino de nomeação de palavras impressas e escrita (ProgLeit $\left.{ }^{\circledR}\right)$, baseado no paradigma de equivalência de estímulos, foi elaborado para avaliar e ensinar esta rede de relações em pequenos passos e de maneira individualizada (de Souza \& de Rose, 2006; Rosa, de Rose, de Souza, Hanna, \& Fonseca, 1998). 
O estudo realizado por Melchiori et al. (2000) relata a aplicação do programa de leitura (ProgLeit ${ }^{\circledR}$ ) a diferentes populações com dificuldades em aprender a nomear palavras impressas, tais como estudantes pré-escolares, estudantes de primeira série do ensino regular, alunos com atraso global do desenvolvimento e adultos não alfabetizados. Baseou-se no ensino das discriminações condicionais entre palavra ditada e palavra impressa e no ensino da construção (cópia) de palavras impressas a partir da seleção das letras ou sílabas componentes das palavras de ensino. A partir desse procedimento, todos os estudantes aprenderam a ler as palavras de treino e, com poucas exceções, as palavras de generalização oriundas da recombinação das unidades menores das palavras de ensino. Todavia, os alunos com atraso global no desenvolvimento apresentaram dificuldade para a leitura generalizada e aprenderam a ler as palavras de treino com uma maior quantidade de sessões e com a inserção de procedimentos remediativos.

A partir da análise das dificuldades que foram encontradas com os participantes do estudo da Melchiori e colaboradores (2000) e com outros participantes com deficiência intelectual em estudos posteriores (e.g. de Freitas, 2009, 2012) e considerando as vantagens do ensino direto do repertório de ecoar para a posterior resposta de nomeação de figuras (e.g. Almeida-Verdu, Bevilacqua, de Souza, \& Souza, 2009; Souza, Almeida-Verdu, \& Bevilacqua, 2013), o presente estudo inseriu o ensino do ecoico como uma das fases do procedimento para verificar os efeitos deste ensino sobre o repertório alvo (nomeação de palavras impressas).

O treino de repertórios expressivos, como ecoar e nomear figuras, pode proporcionar melhora na inteligibilidade da fala de participantes. A inteligibilidade da fala, considerada no escopo deste trabalho como a correspondência ponto a ponto entre a emissão vocal do participante e as convenções estabelecidas pela comunidade verbal, apresenta-se inconsistente em participantes com características de repertório condizentes com o diagnóstico de deficiência intelectual. Em geral, procedimentos de ensino de imitação de palavras (operante verbal ecoico) têm sido efetivos para a posterior resposta de nomeação de figuras (Almeida-Verdu et al., 2009; Souza et al., 2013) e de nomeação de sentenças impressas (Golfeto \& de Souza, 2015) em populações com diferentes necessidades especiais de ensino. Por outro lado, a maior precisão da produção da fala (fala mais inteligível) em tarefas de nomeação de palavras impressas tem sido obtida após a exposição aos programas de ensino baseados no modelo das relações de equivalência, quando eles promovem o controle pelas unidades menores que a palavra, aliados às sucessivas oportunidades de oralizar (Almeida-Verdu et al., 2015; Anastácio-Pessan, Almeida-Verdu, Bevilacqua, \& de Souza, 2015; Neves \& Almeida-Verdu, 2014), no entanto, esses participantes já eram leitores rudimentares.

Considerando que a emissão oral de uma palavra diante da apresentação de um modelo de mesma modalidade (AD) pode ser um repertório mais simples, em contraste à decodificação da palavra impressa (CD) e considerando a necessidade de investigação adicional do uso de procedimentos baseados no paradigma da equivalência de estímulos para o ensino de nomeação de palavras para participantes com deficiência intelectual, o presente trabalho se propôs a verificar a influência do ensino gradual de repertórios discriminativos prévios ao estabelecimento de classes de equivalência, inclusive o operante verbal ecoico, sobre a emergência de nomeação de palavras impressas para duas crianças com deficiência intelectual e com dificuldade em oralizar.

\section{Método}

\section{Participantes}

Dois aprendizes com Síndrome de Down e deficiência intelectual que frequentavam uma escola especial da rede privada no interior de São Paulo. Estes participantes não eram alfabetizados, tinham idades de 8 (A1) e 11 anos (A2) e foram escolhidos, principalmente, por não terem aprendido nomeação em outro estudo (Gomes, 2014) e por apresentarem dificuldades em oralizar. 
Os aprendizes A1 e A2 foram selecionados por apresentar desempenho relacional emergente $\left(\mathrm{BC} / \mathrm{CB}^{2}\right)$ médio abaixo de $30 \%$ no Diagnóstico de Leitura e Escrita ${ }^{3}$ e apresentar repertório nulo em nomeação de palavras impressas (CD). Além desses critérios, os aprendizes deveriam ter frequência diária nas atividades escolares, podendo assim manter alta frequência nas sessões experimentais, uma vez que seriam realizadas na escola.

Os aprendizes selecionados foram previamente autorizados pela família a participarem da pesquisa por meio do Termo de Consentimento Livre e Esclarecido ${ }^{4}$. O repertório dos aprendizes foi caracterizado por meio da consulta ao prontuário diagnóstico, presente na escola, e pela aplicação da Escala de Inteligência Wechsler para Crianças (WISC-III) - Terceira Edição (Wechsler \& Figueiredo, 2002) e do Teste de Vocabulário por Imagens Peabody Picture Vocabulary Test (PPVT-R) - Revised (Dunn \& Dunn, 1981), a fim de mapear o nível de desenvolvimento cognitivo e de vocabulário receptivo de cada um. Estes dados encontram-se na Tabela 1.

\section{Situação Experimental}

A coleta de dados ocorreu em uma sala de aula de uma escola especial da rede privada de ensino, na cidade de São Carlos-SP. A sala era bem iluminada e tinha uma estante com livros e duas mesas com cadeiras. O local era previamente preparado pelo experimentador, de modo a diminuir as variáveis intervenientes, como estímulos distratores, barulho externo e luminosidade.

2 Relacionar uma palavra impressa correspondente a uma figura modelo, assim como relacionar figura correspondente a uma palavra impressa modelo, sem treino direto.

3 Avaliação do repertório de leitura e escrita por meio de tarefas relacionais que se utilizam de processos de discriminação e compõem a rede de relações de equivalência (Fonseca, 1997).

4 O presente estudo foi aprovado pelo Comitê de Ética em Pesquisa com Seres Humanos da Universidade Federal de São Carlos, com parecer $\mathrm{n}^{\mathrm{o}} 112.504 / 2012$.
Esse ambiente experimental era organizado de modo que o aprendiz desempenhasse tarefas computadorizadas que pudessem facilitar o ensino de relações pareadas entre estímulos auditivos e/ou visuais. Os participantes eram levados individualmente para o ambiente de coleta e, ao se sentarem em frente ao computador, eram direcionados à realização dos passos de ensino. $\mathrm{O}$ experimentador permanecia ao lado do aprendiz durante toda tarefa.

As sessões de ensino ocorriam com frequência de cinco dias na semana para cada aprendiz. O limite para a execução dos passos de ensino por sessão dependia da disposição do aluno ao ensino e do seu desempenho de aprendizagem durante o procedimento. Geralmente eles eram expostos a um máximo de três passos consecutivos por sessão, o que determinava o tempo de duração média de, no máximo, 30 minutos por sessão, e depois voltavam para a sala de aula.

\section{Instrumentos e Materiais}

Para a aplicação do procedimento, utilizou-se uma câmera filmadora, um computador portátil e testes psicológicos, WISC-III e PPVT-R. No computador estavam instalados a plataforma Windows e o software "Aprendendo a ler e escrever em pequenos passos" (Rosa et al., 1998), conhecido como Programa de Leitura (ProgLeit $®$ ). A câmera filmadora foi utilizada para gravar as sessões do procedimento para posterior verificação dos dados, sobretudo das vocalizações apresentadas pelos participantes.

O software foi desenvolvido para ensinar e testar habilidades básicas de leitura e escrita, permitindo a programação de tentativas que envolvessem processos de discriminação condicional. Para isso, havia sempre a presença de um estímulo com função de modelo auditivo ou visual, no centro superior da tela, que determinava a escolha de maneira simultânea de um dos estímulos com função de comparação (no máximo três que se localizavam na parte inferior da tela do computador).

A aplicação de programas de ensino construídos no ProgLeit ${ }^{\circledR}$ possibilita, portanto, a aprendizagem de relações arbitrárias, as quais se utilizam de pareamentos entre estímulos auditi- 
Tabela 1

Caracterização dos Aprendizes

\begin{tabular}{|c|c|c|c|c|c|c|c|c|c|}
\hline \multicolumn{2}{|c|}{ Aprendiz } & \multirow[t]{2}{*}{ Idade } & \multirow[t]{2}{*}{$\begin{array}{l}\text { Diagnóstico } \\
\text { médico }\end{array}$} & \multirow[t]{2}{*}{$\begin{array}{l}\text { Especificações } \\
\text { do prontuário }\end{array}$} & \multicolumn{4}{|c|}{ WISC-III } & \multirow[t]{2}{*}{ PPVT-R } \\
\hline & Sexo & & & & Verb & Exec & Total & Classificação & \\
\hline A1 & 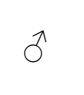 & $8 a$ & $\begin{array}{l}\text { Síndrome } \\
\text { de Down }\end{array}$ & $\begin{array}{l}\text { Dificuldade } \\
\text { na fala }\end{array}$ & 53 & 68 & 57 & $\begin{array}{c}\text { Intelectualmente } \\
\text { deficiente }\end{array}$ & $2 \mathrm{a} 1 \mathrm{~m}$ \\
\hline $\mathrm{A} 2$ & $0^{\pi}$ & $11 \mathrm{a}$ & $\begin{array}{l}\text { Síndrome } \\
\text { de Down }\end{array}$ & $\begin{array}{l}\text { Dificuldade } \\
\text { na fala }\end{array}$ & 47 & 45 & 50 & $\begin{array}{c}\text { Intelectualmente } \\
\text { deficiente }\end{array}$ & $2 \mathrm{a} 1 \mathrm{~m}$ \\
\hline
\end{tabular}

vos e/ou visuais e de execução de tarefas. Essas tarefas englobam a seleção de estímulos, como na relação $\mathrm{AB}$ (palavra ditada-figura), a vocalização diante de um estímulo, como na relação CD (nomeação da palavra impressa), e a composição de um estímulo por unidades menores que o compõe, como a junção de sílabas para formar uma palavra impressa (relação CE). Durante a aplicação do procedimento, o registro das escolhas do participante era realizado pelo computador, por meio do mouse, e todas as respostas de nomeação eram registradas pelo experimentador via teclado.

Os procedimentos de aplicação do programa de ensino empregaram estímulos visuais (figuras, palavras e sílabas impressas) e auditivos (palavras e sílabas ditadas), de modo correspondente à comunidade verbal. As palavras impressas foram selecionadas pelo experimentador, dentre palavras presentes no cotidiano, compostas por três sílabas simples, que seguiam o padrão silábico consoante-vogal. Dessa forma, as duas palavras selecionadas foram "tapete" $\mathrm{e}$ "fivela", apresentadas em letras de imprensa, em fonte Arial e com tamanho 50.

\section{Procedimento Geral}

O ensino de nomeação de palavras impressas proposto envolveu sete passos de ensino que englobaram tipos diferentes de tarefas relacionais. Essas tarefas poderiam favorecer a aprendizagem do repertório de nomeação de palavras impressas por expor os participantes ao treino de repertórios básicos previamente. O procedimento de ensino seguiu um delineamento intra-sujeitos, o qual aplicou medidas de pré e pós-teste entre a intervenção planejada para o ensino de um par de palavras.

O ensino consistiu do estabelecimento de relações condicionais entre palavra ditada-figura $(\mathrm{AB})$ e entre palavra ditada-palavra impressa (AC). Foram ensinadas também relações condicionais de identidade entre figura-figura (BB) e entre palavra impressa-palavra impressa (CC); além das relações expressivas de nomeação de figuras (BD) e de ecoar conforme o modelo auditivo (AD), e de construir a palavra impressa por seleção de sílabas (CE), como um ensino adicional de relações entre estímulos.

O ensino do operante verbal ecoico aliado ao ensino da relação de nomeação de figuras foi o diferencial em relação a estudos anteriores (Almeida-Verdu et al., 2009; Melchiori et al., 2000; Souza et al., 2013) e teve como objetivo avaliar se a melhoria na inteligibilidade da fala dos participantes poderia influenciar o desempenho na nomeação da palavra impressa. As relações emergentes foram testadas baseadas em seleção entre figura-palavra impressa (BC) e palavra impressa-figura (CB) e baseadas na topografia da resposta como a nomeação de palavra impressa (CD). A Tabela 2 evidencia as etapas desse procedimento, cuja descrição encontra-se a seguir.

O pré-teste, etapa anterior à intervenção, buscou avaliar se as relações BC, CB, e CD estavam estabelecidas, sem consequências diferenciais para as respostas e em um total de 28 tentativas ( 2 tentativas $\mathrm{CD}+24$ tentativas de $\mathrm{BC} / \mathrm{CB}$ +2 tentativas de $\mathrm{CD}$ ). Portanto, essa fase avaliou previamente a formação de classes de estímulos entre as palavras de treino e não teve critério de 
Tabela 2

Tipos de Tarefas Adotadas no Pré e Pós-Teste e Ensino, Critério de Aprendizagem e Consequências Programadas para Respostas

\begin{tabular}{|c|c|c|c|c|c|c|c|c|c|c|c|c|}
\hline \multirow{2}{*}{ Etapas } & \multirow{2}{*}{$\begin{array}{c}\mathrm{N}^{o} \mathrm{de} \\
\mathrm{ttvs}\end{array}$} & \multicolumn{9}{|c|}{ Tipo de tarefa } & \multirow{2}{*}{$\begin{array}{c}\text { Critério de } \\
\text { Aprendizagem }\end{array}$} & \multirow{2}{*}{$\begin{array}{c}\text { Consequência } \\
\text { programada }\end{array}$} \\
\hline & & $\mathrm{AB}$ & $\mathrm{AC}$ & $\mathrm{BB}$ & $\mathrm{CC}$ & $\mathrm{CE}$ & $\mathrm{BD}^{*}$ & $\mathrm{BC}$ & $\mathrm{CB}$ & $\mathrm{CD}$ & & \\
\hline Pré-teste & 28 & & & & & & & $\sqrt{ }$ & $\sqrt{ }$ & $\sqrt{ }$ & - & - \\
\hline $\mathrm{P} 1$ & 28 & $\sqrt{ }$ & & & $\sqrt{ }$ & & $\sqrt{ }$ & & & & $100 \%$ & $\sqrt{ }$ \\
\hline $\mathrm{P} 2$ & 26 & $\sqrt{ }$ & $\sqrt{ }$ & $\sqrt{ }$ & & & & & & & $100 \%$ & $\sqrt{ }$ \\
\hline P3 & 22 & $\sqrt{ }$ & $\sqrt{ }$ & & $\sqrt{ }$ & & $\sqrt{ }$ & & & & $100 \%$ & $\sqrt{ }$ \\
\hline P4 & 22 & $\sqrt{ }$ & $\sqrt{ }$ & & & $\sqrt{ }$ & & & & & $100 \%$ & $\sqrt{ }$ \\
\hline P5 & 22 & $\sqrt{ }$ & $\sqrt{ }$ & & & $\sqrt{ }$ & & & & & $100 \%$ & $\sqrt{ }$ \\
\hline P6 & 28 & $\sqrt{ }$ & $\sqrt{ }$ & & & & $\sqrt{ }$ & & & & $100 \%$ & $\sqrt{ }$ \\
\hline $\mathrm{P} 7$ & 18 & $\sqrt{ }$ & $\sqrt{ }$ & $\sqrt{ }$ & $\sqrt{ }$ & $\sqrt{ }$ & $\sqrt{ }$ & & & & $100 \%$ & $\sqrt{ }$ \\
\hline Pós-teste & 28 & & & & & & & $\sqrt{ }$ & $\sqrt{ }$ & $\sqrt{ }$ & - & - \\
\hline
\end{tabular}

Nota. P: passo de ensino; A: palavra ditada; B: figura; C: palavra impressa; D: nomeação; E: resposta de construção de palavras por sílabas; * sem critério sistemático de aprendizagem e com treino de ecoico (AD); ttvs: tentativas.

aprendizagem para que o aluno avançasse para a próxima etapa. As duas tentativas $\mathrm{CD}$ antes e depois do teste $\mathrm{BC} / \mathrm{CB}$ (tentativas com apenas dois estímulos de comparação) buscavam controlar se a consistência na repetição das relações poderia ter ensinado algo aos participantes.

$\mathrm{O}$ ensino foi concentrado em sete passos, com consequências diferenciais para os acertos e erros dos aprendizes. Cada participante era submetido a todos os passos de ensino, podendo repeti-los em ordem que não era a linear ( $\mathrm{P} 2$, P5, P3...) até atingir o critério de aprendizagem preestabelecido para cada passo. Esse critério era de $100 \%$ de acertos em todas as tentativas (exceto para $\mathrm{BD}$ e $\mathrm{AD}$, devido às limitações de vocalização dos participantes), mesmo que fosse necessário repetir os passos de uma maneira não linear.

$\mathrm{O}$ ensino iniciava com o passo P1 que expunha o participante ao ensino de relações condicionais entre palavra ditada e figura $(\mathrm{AB})$, de identidade de palavras (CC) e de nomeação de figuras (BD), com ensino de ecoico (AD) adicional. Cada passo tinha um foco de ensino específico em um tipo de relação condicional entre estímulos ou entre estímulos e respostas, porém incluía relações complementares aos passos seguintes. Esse arranjo da rotina de ensino tinha como finalidade antecipar uma maior exigência de controle de estímulos, de maneira gradual, por um lado; por outro, podia motivar o aluno com as tentativas previamente aprendidas mantendo a ocorrência de acertos.

$\mathrm{O}$ passo $\mathrm{P} 2$, além da relação entre palavra ditada e figura $(\mathrm{AB})$, incluiu a relação entre palavra ditada e palavra impressa (AC) e identidade entre figuras (BB). O passo $\mathrm{P} 3$ foi análogo ao passo $\mathrm{P} 1$, porém incluiu a relação entre palavra ditada e palavra impressa (AC), recém-treinada no passo P2. Os passos P4 e P5 eram idênticos nas relações ensinadas entre palavra ditada $\mathrm{e}$ figura $(\mathrm{AB})$ e palavra ditada e palavra impressa (AC), contudo eram treinos específicos para cada palavra de ensino, com o acréscimo da relação de cópia por construção (CE). O passo P6 expôs os participantes às relações condicionais auditivo-visuais ( $\mathrm{AB}$ e $\mathrm{AC}$ ) e retomou o treino de nomeação de figuras (BD), com ensino de ecoico (AD) adicional. O passo P7 expôs os participantes a todas as relações entre estímulos e entre estímulos e respostas treinadas nos passos anteriores. 
As tentativas por passo eram planejadas com a mesma quantidade de relações para cada palavra isolada a ser ensinada. Os alunos conseguiriam, portanto, avançar nos passos de ensino ao serem expostos às outras tarefas, mesmo não acertando de início todas as tentativas, de modo a não deixar o ensino repetitivo e cansativo. De maneira sintética, a complexidade gradual do ensino focou-se inicialmente nas tarefas $\mathrm{AB}$, pelos aprendizes terem apresentado o desempenho de $100 \%$ no pós-teste (com palavras diferentes) do estudo anterior (Gomes, 2014), o que facilitaria a aprendizagem da relação AC. Treinaram-se, em seguida, tarefas de identidade (BB ou $\mathrm{CC})$, por serem relações teoricamente simples, o que aumentaria a probabilidade de acerto para o aprendiz. As relações $\mathrm{BD}$ e $\mathrm{AD}$ foram ensinadas de maneira assistemática, a fim de minimizar a limitação de vocalização dos aprendizes. Depois foram as relações $\mathrm{CE}$, para aumentar o controle discriminativo pelas unidades mínimas, as quais formavam as palavras de ensino.

Metade das tentativas foi programada com letras maiúsculas e a outra metade com letras minúsculas, de forma a proporcionar a transição entre tipos de letras. As consequências programadas para as respostas convencionadas como corretas eram elogios e/ou efeito sonoro e/ou imagens animadas com duração de cinco segundos; e as consequências programadas para as respostas convencionadas como incorretas era a frase corretiva "Não, não é!" e o retorno para a tentativa, como oportunidade de mudança da escolha de resposta. Cada tentativa só poderia ser repetida até cinco vezes, a fim de não se encerrar o passo.

Em geral, a estrutura do procedimento segue passos de ensino, que eram compostos por tentativas nas quais os estímulos de comparação iam aumentando de quantidade na tela do computador, um a um, até completar três estímulos de comparação. Para as tentativas que envolviam respostas de construção de palavras por sílabas (CE), estas poderiam exceder a quantidade de três estímulos de construção na parte inferior da tela. As sílabas iam sendo acrescentadas uma a uma até ter o número suficiente ou mais de sílabas que formassem a palavra modelo, como forma de modelar a resposta correta.
Assim, para cada tipo de tarefa a ser ensinada era aumentada a exigência de aprendizagem de maneira gradativa, como pode ser visto na Figura 1. Apenas um estímulo de comparação seria selecionado de acordo com o estímulo modelo presente.

A repetição dos mesmos tipos de tarefas, durante os passos de ensino, era uma estratégia de verificação da presença de respostas consistentes às tentativas de ensino. Isso também mesclava as tarefas consideradas mais difíceis com tarefas consideradas mais fáceis, o que garantiria em cada passo uma maior probabilidade de respostas corretas, assim como de consequências reforçadoras.

O pós-teste foi a etapa posterior à intervenção e aplicou a mesma estrutura do pré-teste para avaliar a ocorrência da formação de classes de equivalência entre as palavras de treino e, assim, averiguar a efetividade do ensino de repertórios relacionais básicos sobre a aprendizagem do repertório de nomeação de palavras impressas.

\section{Análise de Dados}

Os dados foram analisados de modo a verificar o desempenho individual dos participantes relacionado à formação de classes de equivalência, para assim constatar a alteração no repertório de nomeação de duas palavras isoladas a partir do ensino de suas habilidades relacionais básicas. Com isso, quantificou-se a frequência de respostas antes e depois da intervenção para as tarefas relacionais entre figuras e palavras impressas (BC e $\mathrm{CB}$ ) e nomeação dessas pala$\operatorname{vras}(\mathrm{CD})$.

As respostas de nomeação foram categorizadas de acordo com a correspondência (ou não) com as convenções da comunidade verbal, o que resultou em quatro categorias: Nomeação Total: nomeação com correspondência ponto a ponto com as convenções da comunidade verbal; Nomeação Parcial: nomeação com trocas (p. ex. tatepe ou tabete, em vez de tapete), omissões de fonemas ou forma silabada (p. ex. _iela, em vez de fivela); Nomeação Sem correspondência: qualquer resposta sem convenção com a comunidade verbal (p. ex. ui, em vez de fivela); Sem resposta: nenhuma resposta era emitida. 

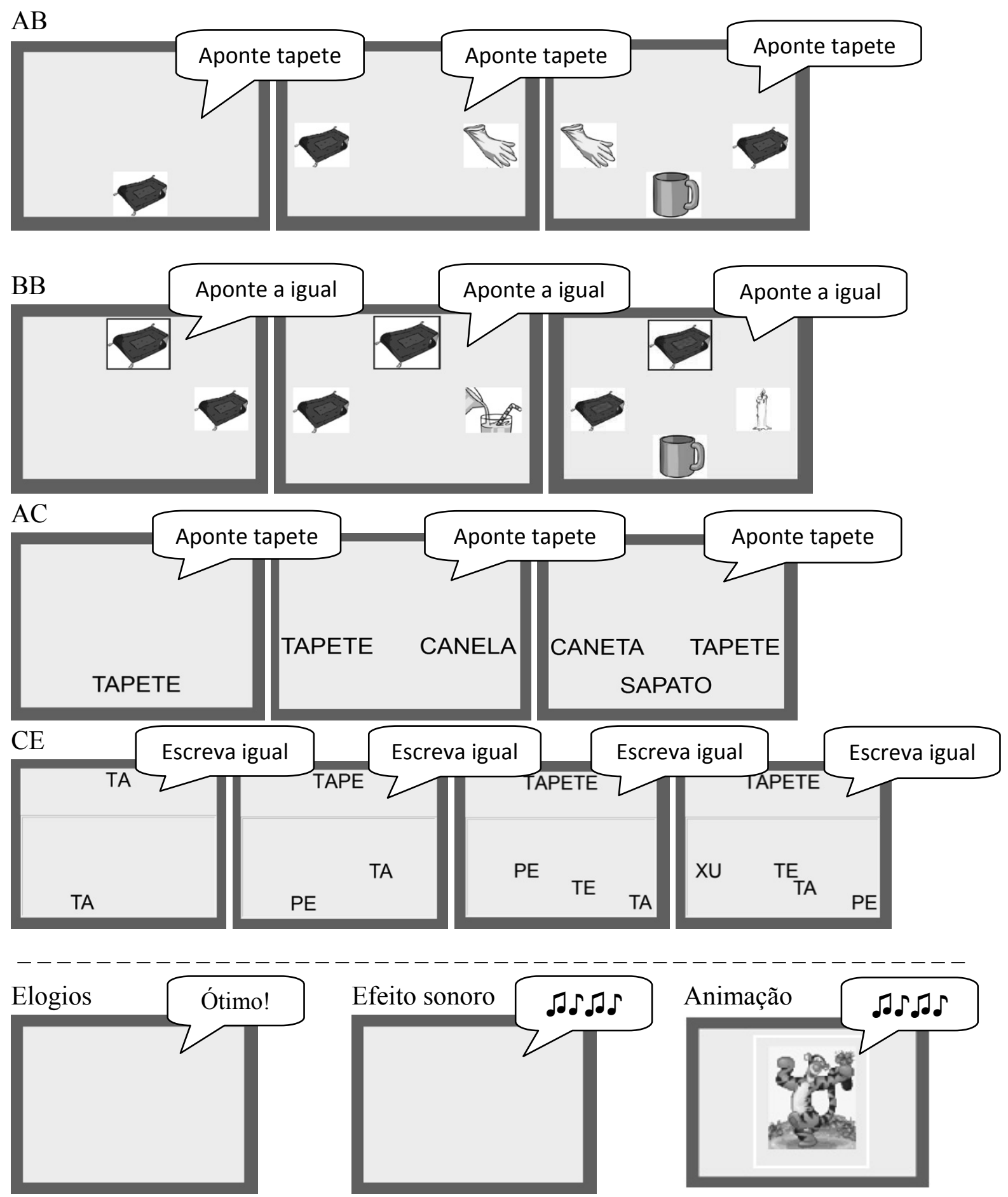

Figura 1. Representação de algumas das tarefas ensinadas, e que evidenciam a inserção gradual dos estímulos de comparação (da esquerda para a direita), durante o ensino das relações AB, BB, AC e CE. Nos balões estão reproduzidas as instruções para cada tipo de relação. A parte inferior da figura simula as possíveis consequências para o acerto.

\section{Resultados}

Os dados dos participantes possibilitaram a avaliação do desempenho em tarefas que fazem parte da rede de relações do repertório de nome- ação para a formação de classes de estímulos entre figuras, palavras ditadas e palavras impressas. Como resultado, observou-se que o ensino de relações condicionais consideradas pré-requisito à nomeação, tais como as relações de 
identidade entre estímulos (BB e CC), de seleção de figuras e de palavras impressas conforme um estímulo modelo auditivo ( $\mathrm{AB}$ e $\mathrm{AC}$ ), de construção de palavra impressa conforme a mesma palavra como modelo (CE), de nomeação de figuras (BD) e de ecoar conforme o modelo auditi- vo (AD), aumentou a probabilidade da presença de relações emergentes entre figuras e palavras impressas (BC), palavras impressas e figuras (CB) e a nomeação de palavras impressas (CD). A porcentagem de acertos nas relações $\mathrm{BC}, \mathrm{CB}$ e $\mathrm{CD}$ indicou a efetividade da intervenção proposta, como pode ser visto na Figura 2.
Pré-teste

A1
Pós-teste

A2
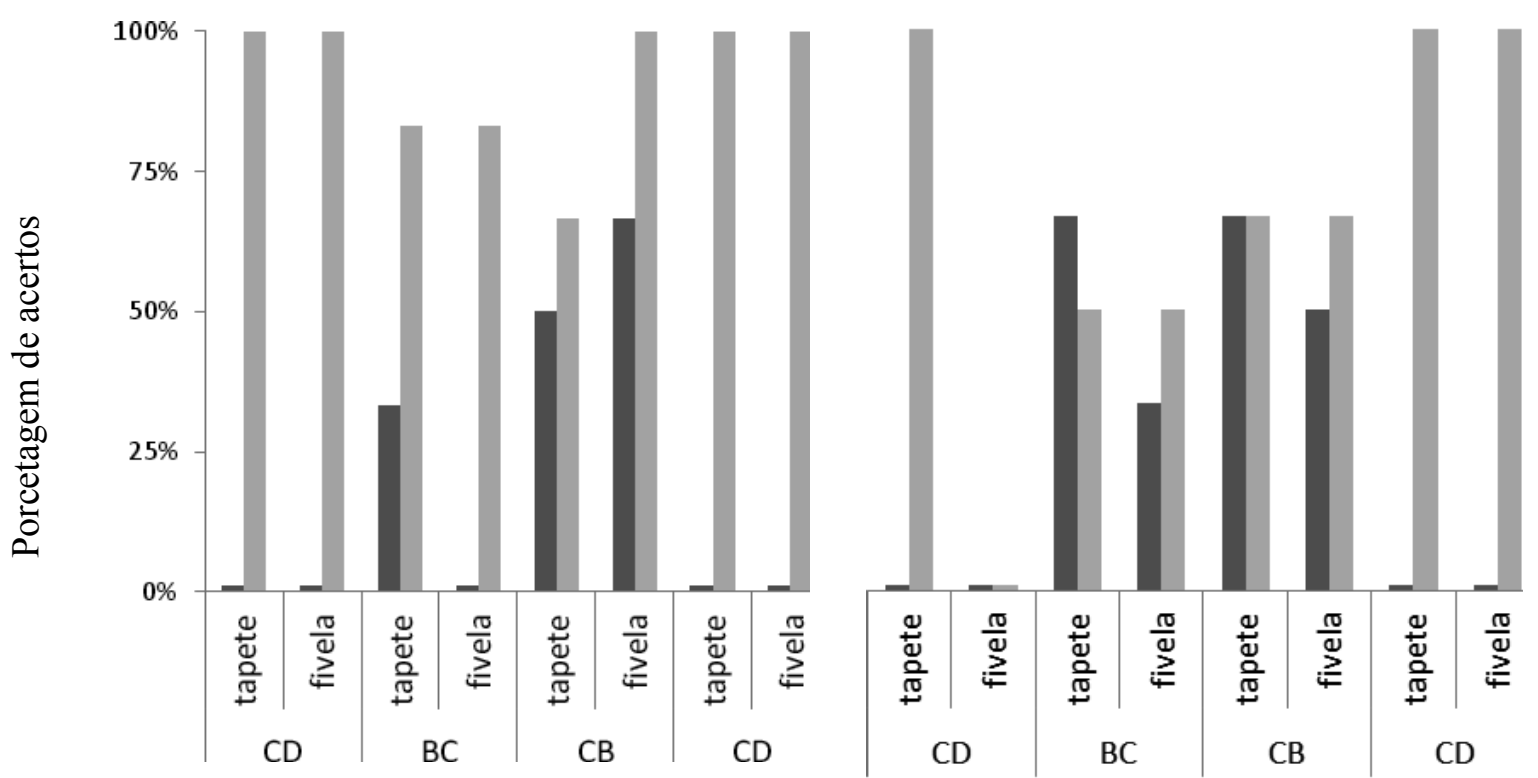

Figura 2. Porcentagem de acertos dos participantes no pré (barras cinza escuro) e pós-teste (barras cinza claro) para o ensino de repertórios básicos.

De acordo com a Figura 2, durante o pré-teste (barras cinza escuro), ambos os participantes apresentaram baixa porcentagem de acertos para as tarefas relacionais emergentes $\mathrm{BC} / \mathrm{CB}$ (A1: $37 \%$ e A2: $54 \%$ ) e para a nomeação de palavras - CD (ambos os aprendizes com desempenho nulo), o que evidenciou a ausência de formação de classes de estímulos para as palavras "tapete" e "fivela". As relações BC e CB exigiram respostas de seleção de estímulos e, havendo duas possibilidades de escolha, as respostas consideradas corretas provavelmente ocorreram ao acaso.

Com isso, aplicou-se a intervenção por meio de passos de ensino para ensinar gradualmente as relações $\mathrm{BB}, \mathrm{CC}, \mathrm{BD}, \mathrm{AD}, \mathrm{AB}, \mathrm{AC}$, e CE. Os resultados dos participantes, representados pelo número de repetições desses passos de ensino até a obtenção do critério de acertos, encontram-se na Tabela 3; nessa tabela, a relação de maior dificuldade pode ser identificada pela maior frequência de repetições ao referido passo de ensino. Nesse caso, desconsideram-se os comportamentos de nomeação de figuras (BD) e de ecoico (AD), por serem relações que não seguiam o critério de aprendizagem de maneira sistemática.

De acordo com a Tabela 3, as relações envolvendo a seleção de palavra impressa mediante a palavra ditada (AC) foram as de maior dificuldade para os participantes, demandando o maior número de repetições de até 3 exposições para $\mathrm{A} 1$ e até 8 exposições para $\mathrm{A} 2$, sendo que A2 apresentou mais dificuldade que A1. 
Tabela 3

Passo de Ensino / $\mathbf{N}^{0}$ de Repetições / Tarefa de Ensino com Maior Dificuldade

\begin{tabular}{|c|c|c|c|c|c|c|c|c|c|c|c|}
\hline $\mathrm{A} 1$ & $\mathrm{AB}$ & $\mathrm{AC}$ & $\mathrm{BB}$ & $\mathrm{CC}$ & $\mathrm{CE}$ & $\mathrm{A} 2$ & $\mathrm{AB}$ & $\mathrm{AC}$ & $\mathrm{BB}$ & $\mathrm{CC}$ & $\mathrm{CE}$ \\
\hline $\mathrm{P} 1$ & 2 & & & & & $\mathrm{P} 1$ & 5 & & & & \\
\hline P2 & & 1 & & & & $\mathrm{P} 2$ & & 7 & & & \\
\hline P3 & & 3 & & & & $\mathrm{P} 3$ & & 8 & & 8 & \\
\hline P4 & & 2 & & & 2 & $\mathrm{P} 4$ & & & & & 2 \\
\hline P5 & & & & & 1 & P5 & & 4 & & & 4 \\
\hline P6 & & & & & & P6 & & 6 & & & \\
\hline P7 & & 3 & & & 3 & P7 & & 7 & & & 7 \\
\hline
\end{tabular}

Percebe-se que, para A1, o procedimento de ensino, em geral - ensino de relações consideradas pré-requisito para a nomeação de palavras, tais como em relacionar figuras iguais (BB), palavras impressas iguais $(\mathrm{CC})$, palavra ditada com suas respectivas figuras $(\mathrm{AB})$ ou com palavras impressas (AC), nomear figuras (BD), ecoar palavras ditadas $(\mathrm{AD})$ e formar a palavra impressa mediante a própria palavra, por meio de unidades menores tais como sílabas (CE) foi efetivo para alterar o seu padrão de respostas diante das tarefas não diretamente ensinadas $\mathrm{BC}, \mathrm{CB}$ e $\mathrm{CD}$ para as duas palavras isoladas. Durante o pós-teste (barras cinza claro da Figura 2), A1 leu corretamente todas as tentativas $\mathrm{CD}$ e manteve desempenho, em média, acima de $80 \%$ para as tentativas $\mathrm{BC} / \mathrm{CB}$.

$\mathrm{O}$ mesmo ensino não foi tão efetivo para o participante A2 se comparado com o desempenho apresentado por A1, cujas respostas de seleção saíram da zona do acaso após o procedimento. A2 foi exposto a um número maior de repetições das sessões de ensino e, durante o pós-teste, nomeou "tapete" nas duas tentativas iniciais de $\mathrm{CD}$, obteve desempenho abaixo de $75 \%$ para as tentativas $\mathrm{BC} / \mathrm{CB}$ e leu (parcialmente) de forma correta as outras duas tentativas de $\mathrm{CD}$. Os resultados em $\mathrm{BC} / \mathrm{CB}$ indicaram que o participante $\mathrm{A} 2$ não estabeleceu relações de equivalência entre os estímulos figura e palavra impressa de maneira consistente, ainda que tenha atingido o critério de aprendizagem durante o procedimento de ensino. Todavia, ao se comparar a porcentagem de acertos obtida por
A2 com seu próprio repertório inicial, nota-se melhora, isto é, um aumento no percentual de acertos.

As respostas de nomeação de palavras impressas dos participantes foram exigidas diferentemente conforme a dificuldade de vocalizações de cada indivíduo. Assim, ambos os participantes iniciaram o procedimento não conseguindo ler as palavras de ensino "tapete" e "fivela", emitindo apenas vocalizações monossilábicas do tipo "ui" ou "i". No pós-teste, observou-se que os dois indivíduos tinham adquirido a função considerada correta para a nomeação das palavras de ensino, isto é, emitiram vocalizações topograficamente diferentes diante das duas palavras impressas e mais proximamente das convenções definidas pela comunidade verbal. Para A1, cuja dificuldade em vocalizar era menor do que a de A2, a topografia vocal final emitida foi "apete" e "fivela", e, para A2, a topografia produzida foi "pepete" e "favela". A Figura 3 categoriza o desempenho em nomeação dos participantes para todas as tentativas CD no pré e pós-teste.

Pela categorização do desempenho em nomeação demonstrada na Figura 3, percebe-se que o procedimento de ensino melhorou a vocalização e a inteligibilidade da fala dos aprendizes para os seus repertórios de nomeação de palavra impressa. O participante $\mathrm{A} 1$ obteve porcentagem de erros concentrada em palavras sem correspondência $(100 \%)$ no pré-teste e, após o ensino, apresentou $75 \%$ de acertos de nomeação de palavra total e apenas uma palavra emitiu de modo 
Pré-teste

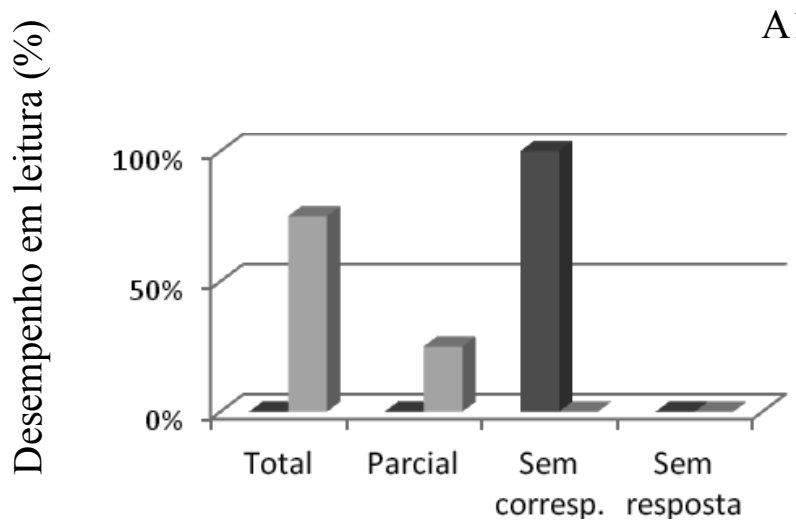

Pós-teste

A 1

A2

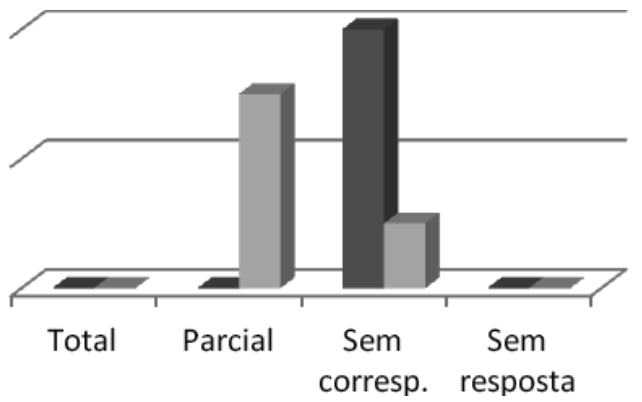

Figura 3. Categorização do desempenho em leitura dos participantes para as palavras de ensino no Pré (barras cinza escuro) e Pós-teste (barras cinza claro).

parcial (25\%, com função correta). O participante $\mathrm{A} 2$, cuja porcentagem de acertos na palavra total foi nula, mesmo no pós-teste, após o ensino saiu de uma porcentagem de erros concentrada em palavras sem correspondência (100\%) para uma porcentagem de acertos parciais $(75 \%$ dos componentes das palavras considerados corretos, tal como demonstra a Figura 2). Portanto, o procedimento possibilitou aos participantes modificar a topografia vocal emitida diante da palavra impressa, errando bem menos, e sendo apresentada cada vez mais próxima às convenções definidas pela comunidade verbal.

Desse modo, a alteração dos padrões de resposta para as relações consideradas emergentes e relacionadas à nomeação de palavras impressas foi demonstrada ao se comparar de maneira individual o pré e o pós-teste dos participantes. Assim, os desempenhos nas tarefas relacionais emergentes passaram de $45 \%$ (em média, avaliados no pré-teste) para $77 \%$ (em média, avaliados no pós-teste) e os aprendizes, que antes apresentavam repertório nulo de nomeação de palavras, passaram a ler as duas palavras ensinadas.

\section{Discussão}

O ensino de repertórios discriminativos prévios ao estabelecimento de classes de equivalência, com destaque para o ensino de repertórios de ecoico e nomeação de figuras, pode ter oferecido condições para a formação de classes de equivalência e extensões das relações de controle de estímulos para a nomeação de palavras isoladas para dois participantes com deficiência intelectual e com histórico de fracasso na aprendizagem desses repertórios. Estudos anteriores utilizaram o mesmo programa de ensino com participantes com deficiência intelectual e mostraram avanços no ensino de nomeação de palavras, porém, verificou-se um número elevado de repetições das sessões e de tentativas (e.g. de Freitas, 2009, 2012; Melchiori et al., 2000).

Alguns estudos realizados com crianças com deficiência auditiva demonstraram que quando essas são capazes de ler com precisão (os grafemas funcionando como pistas para a emissão do fonema definido como correto), o controle exercido pela palavra impressa se estende para a figura após o fortalecimento das classes de equivalência entre figura, palavra ditada e palavra impressa. Dessa forma, as crianças passam a emitir vocalizações mais precisas na presença da figura (Anastácio-Pessan et al., 2015; Lucchesi, Almeida-Verdu, Buffa, \& Bevilacqua, 2015). De maneira análoga, no presente estudo, se os participantes passaram a emitir vocalizações mais precisas em nomeação de figuras após o treino de ecoico, o controle exercido pelas figuras, após a formação de classes de equivalência, passou a ser exercido pelas palavras impressas.

De Freitas (2012) também utilizou o ensino de ecoico com uma criança com deficiência intelectual, como um procedimento de ensino pon- 
tual e remediativo, que forneceu indícios da sua possível efetividade para a ocorrência da nomeação de palavras impressas por esta população. A partir disso, o presente estudo teve como alvo planejar o ensino de uma série de repertórios discriminativos que compõe parte da rede de leitura (como fizeram outros estudos) e inseriu o ecoico a essa rede de relações de ensino.

Os participantes A1 e A2 evoluíram rapidamente durante o procedimento de ensino com o ganho de repertório relacional, o qual era garantido pelos critérios de aprendizagem, e passaram a ler de maneira funcional as palavras de ensino "tapete" e "fivela". Todavia, A2 teve um desempenho inferior para a formação de classes de estímulos durante os testes, embora tenha repetido mais vezes as sessões de ensino e tenha atingido os critérios de aprendizagem preestabelecidos.

Alguns problemas articulatórios de pessoas com Síndrome de Down foram considerados (ver Barata \& Branco, 2010) para, assim, a função da nomeação de palavras impressas dos participantes ser considerada correta. Considerou-se como função correta da nomeação de palavras, as respostas vocais que, mesmo não tendo correspondência ponto a ponto com as convenções definidas pela comunidade verbal, fossem topograficamente diferentes entre si (resposta diante de FIVELA e diante de TAPETE), que tivessem consistência ao longo das tentativas e que tivessem componentes da resposta correta. Neste caso, os erros articulatórios que ocorreram podem ter sido, simplesmente, a melhor articulação possível. De modo semelhante, a dificuldade em emitir vocalizações corretas também é observada na análise de vocalizações de crianças com implante coclear (ver Almeida-Verdu et al., 2009; Almeida-Verdu, Matos, Battaglini, Bevilacqua, \& de Souza, 2012; Golfeto, 2010).

Como os procedimentos de ensino de imitação de palavras (operante verbal ecoico) têm sido efetivos para a posterior resposta de nomeação de figuras em populações com deficiência auditiva (Almeida-Verdu et al., 2009; Souza et al., 2013), acrescentar o treino das relações BD e $\mathrm{AD}$ à rede de relações de equivalência facilitou a nomeação dos participantes diante da palavra impressa, pela extensão do controle exercido pela figura para a palavra impressa.

As repetições das sessões de ensino para ambos os participantes ainda ocorreram com certa frequência e em maior quantidade para um dos participantes (A2), o qual apresentava maior dificuldade em oralizar. A quantidade de palavras ensinadas, apenas duas, dificultou uma avaliação mais ampla do repertório de nomeação de palavras dos participantes. Outras limitações foram encontradas, como o fato dos testes de relações emergentes ocorrerem em extinção e dificultarem a mensuração do estabelecimento de classes de equivalência, principalmente para o aprendiz A2. A ausência de consequências que sinalizassem o acerto ou o erro para as respostas solicitadas nos testes fez com que A2, em situação de teste em extinção, selecionasse de forma aleatória as respostas e buscasse as consequências oferecidas durante o ensino, ao levantar a mão como forma de cumprimento, empurrar a mesa do computador e emitir sons vocálicos característicos de irritação.

Os testes realizados em extinção tinham a finalidade de verificar a acurácia das relações emergentes, de modo que o uso da consequência reforçadora não pudesse ensinar ao indivíduo as relações verificadas. Essa escolha metodológica de aplicar testes em extinção sem um preparo gradativo para a retirada da consequência reforçadora difere de outros estudos nos quais se aplica a consequência reforçadora contingente à participação do indivíduo, não ao seu desempenho (e.g. Resende, Elias, \& Goyos, 2012; Zaine, Domeniconi, \& de Rose, 2014), ou se utiliza dessas consequências especificamente para as escolhas consideradas corretas (e.g. Domeniconi, 2002; Schusterman \& Kastak, 1993; Velasco, Huziwara, Machado, \& Tomanari, 2010). Outra forma de se planejar a verificação da aprendizagem é por meio da alternância entre tentativas reforçadas e não reforçadas e do esvanecimento da consequência reforçadora até chegar a testes em extinção (e.g. Medeiros \& Silva, 2002; Sidman et al., 1989), de modo a preparar os participantes para a situação de teste de relações emergentes. 
Domeniconi (2002) argumenta que a realização de testes que mantêm reforços programados sistematicamente ao desempenho considerado correto busca evitar a inserção de uma variável interveniente (o não reforçamento para as respostas) na situação de teste. Algumas das razões dadas pela autora para o uso de testes com reforço programado é o fato de evitar reações de esquiva e queda motivacionais para os indivíduos, de desviar-se da interferência de outros eventos e de aumentar a probabilidade do engajamento dos participantes na tarefa de teste, por esses indivíduos continuarem nas mesmas condições de reforçamento durante a aplicação de todo o procedimento. Todavia, quando o teste ocorre em extinção a dica de manutenção ou não de uma resposta não é apresentada e isso dificulta o desempenho do participante. Por isso, provavelmente o desempenho de $\mathrm{A} 2$ no teste não foi tão bom quanto na etapa de ensino.

Pensando-se na gradualidade do ensino e nas dificuldades de aprendizagem de participantes com deficiência intelectual, mesclaram-se tentativas com letras maiúsculas e minúsculas como forma de expor e preparar os aprendizes para os dois tipos de letras. Essa decisão baseou-se em de Freitas (2012) que demonstrou que o uso de estímulos textuais grafados em letras maiúsculas proporcionava ganhos nas habilidades relacionais, por aumentar a discriminabilidade dos aprendizes com deficiência intelectual. Outra razão foi que os participantes deste estudo eram expostos na escola especial a alguns materiais didáticos com letras em fonte minúscula.

Em suma, com este estudo, pode-se demonstrar a eficácia do ensino de repertórios prévios ao estabelecimento de classes de equivalência, pois as duas palavras ensinadas passaram a estabelecer controle de estímulos no comportamento verbal dos participantes.

\section{Considerações Finais}

De maneira geral, um ensino estruturado de forma gradual e com critérios de aprendizagem estabelecidos durante os passos do procedimento ajudam a proporcionar um aumento da efetividade do ensino e da aprendizagem. Estes repertórios se estabelecem com a repetição dos passos de ensino e com o alcance do critério, o que possibilita uma maior acurácia e retenção de repertórios previamente aprendidos, embora não garanta necessariamente a emergência de novas relações.

Desta forma, um procedimento que se utiliza de discriminações condicionais de maneira gradativa (de relações mais simples - identidade entre estímulos, pareamento entre palavra ditada e figuras - para relações mais complexas pareamentos entre figuras e palavras impressas, construção de palavras por unidades menores) prepararia um ensino de habilidades básicas para a posterior aquisição de um repertório mais complexo, como a leitura com compreensão. O ensino gradual de habilidades básicas proporcionou a aprendizagem deste repertório e validou uma programação de ensino mais simples e dividida em pequenos passos. Isso facilitou, portanto, a formação de classes de equivalência e possibilitou a nomeação de palavras isoladas.

Com isso, indica-se que mais trabalhos sejam realizados com pessoas com deficiência intelectual e dificuldades na fala, a fim de ampliar o procedimento de ensino com mais palavras (tanto de ensino como de generalização), com mais participantes e, principalmente, com critério sistemático nas tentativas relacionadas ao comportamento expressivo (relações BD e AD). Sugerem-se também, para as próximas pesquisas, alterações no teste que averigua a aquisição do repertório relacional, como inserir consequências reforçadoras para aumentar a adesão do participante no final do procedimento.

\section{Referências}

Almeida-Verdu, A. C. M., Bevilacqua, M. C., de Souza, D. G., \& Souza, F. C. (2009). Imitação vocal e nomeação de figuras em deficientes auditivos usuários de implante coclear: Estudo exploratório. Revista Brasileira de Análise do Comportamento, 5(1), 63-78.

Almeida-Verdu, A. C. M., Giacheti, C. M., Lucchesi, F. M., Freitas, G. R., Dutka, J. C. R., Rovaris, J. A., \& Marques, P. F. (2015). Apraxia e produção da fala: Efeitos do fortalecimento de relações verbais. Revista CEFAC, 17, 974-983. 
Almeida-Verdu, A. C. M., Matos, F. O., Battaglini, M. P., Bevilacqua, M. C., \& de Souza, D. G. (2012). Desempenho de seleção e nomeação de figuras em crianças com deficiência auditiva com implante coclear. Temas em Psicologia, 20(1), 189-202.

Anastácio-Pessan, F. L., Almeida-Verdu, A. C., Bevilacqua, M. C., \& de Souza, D. G. (2015). Usando o paradigma de equivalência para aumentar a correspondência na fala de crianças com implante coclear na nomeação de figuras e na leitura. Psicologia: Reflexão e Crítica, 28(2), 365-377.

Barata, L. F., \& Branco, A. (2010). Os distúrbios fonoarticulatórios na Síndrome de Down e a intervenção precoce. Revista CEFAC, 12(1), 134-139.

Bevilacqua, M. C., \& Souza, D. G. (2012). A criança com deficiencia auditiva na escola: Sistema de FM. São Carlos, SP: Cubo.

Catania, C. A. (1999). Aprendizagem: COMPORTAMENTO, linguagem e cognição (D. G. de Souza, Trad.). Porto Alegre, RS: Artmed.

De Freitas, M. C. (2009). Programação de ensino de leitura e escrita para crianças com deficiência mental (Dissertação de mestrado, Programa de Pós-graduação em Educação Especial, Universidade Federal de São Carlos, SP, Brasil).

De Freitas, M. C. (2012). Construção de um programa de ensino de pré-requisitos de leitura e escrita para pessoas com deficiência intelectual (Tese de doutorado, Programa de Pós-graduação em Psicologia, Universidade Federal de São Carlos, SP, Brasil)

De Rose, J. C. C. (1993). Classes de estímulos: Implicações para uma análise comportamental da cognição. Psicologia: Teoria e Pesquisa, 9(2), 283-303.

De Rose, J. C. (2005). Análise comportamental da aprendizagem de leitura e escrita. Revista Brasileira de Análise do Comportamento, 1(1), 29-50.

De Rose, J. C., \& Bortoloti, R. (2007). A equivalência de estímulos como modelo do significado. Acta Comportamentalia, 15(3), 83-102.

De Rose, J. C., de Souza, D. G., Rossito, A. L., \& de Rose, T. M. S. (1989). Aquisição de leitura após história de fracasso escolar: Equivalência de estímulos e generalização. Psicologia: Teoria e Pesquisa, 5, 325-346.

De Souza, D. G., \& de Rose, J. C. (2006). Desen- volvendo programas individualizados para o ensi- no de leitura. Acta Comportamentalia, 14(1), 77-98.

Domeniconi, C. (2002). Análise de controle restrito de estímulos na aprendizagem de leitura de palavras por indivíduos com Síndrome de Down (Dissertação de mestrado, Programa de Pós-graduação em Educação Especial, Universidade Federal de São Carlos, SP, Brasil).

Dunn, L. M., \& Dunn, L. M. (1981). Peabody Picture Vocabulary Test: Revised. Circle Pines, MN: American Guidance Service.

Fonseca, M. L. (1997). Diagnóstico de repertórios iniciais de leitura e escrita: Uma análise baseada na concepção de relações de equivalência (Dissertação de mestrado, Programa de Pósgraduação em Educação Especial, Universidade Federal de São Carlos, SP, Brasil).

Golfeto, R. M. (2010). Compreensão e produção de fala em crianças com surdez pré-lingual usuárias de implante coclear (Tese de doutorado, Programa de Pós-graduação em Educação Especial, Universidade Federal de São Carlos, SP, Brasil).

Golfeto, R. M., \& de Souza, D. G. (2015). Sentence production after listener and echoic training by prelingual deaf children with cochlear implants. Journal of Applied Behavior Analysis, 48(2), 363-375. doi:10.1002/jaba.197

Gomes, M. L. de C. (2014). Ensino de leitura com diferentes treinos discriminativos a aprendizes com deficiência intelectual (Dissertação de mestrado, Programa de Pós-graduação em Psicologia, Universidade Federal de São Carlos, SP, Brasil).

Lucchesi, F. M., Almeida-Verdu, A. C. M., Buffa, M. J. M. B., \& Bevilacqua, M. C. (2015). Leitura e Inteligibilidade da Fala: Efeitos de ensino programado com crianças usuárias de implante coclear. Psicologia: Reflexão e Crítica, 28(3), 500-510.

Medeiros, J. G., \& Silva, R. M. F. (2002). Efeitos de testes de leitura sobre a generalização em crianças em processo de alfabetização. Psicologia: Reflexão e Crítica, 15(3), 587-602.

Melchiori, L. E., de Souza, D. G., \& de Rose, J. C. (2000). Reading, equivalence and recombination of units: A replication with students with different learning histories. Journal of Applied Behavior Analysis, 33, 97-100. doi:10.1901/ jaba.2000.33-97 
Neves, A. J., \& Almeida-Verdu, A. C. M. (2014). Efeitos de ensino envolvendo equivalência entre palavra ditada, palavra escrita e objeto sobre a inteligibilidade da fala em adolescente com hipoplasia cerebelar. Revista CEFAC, 16(4), 1340-1350.

Pereira, V. A., \& Almeida-Verdu, A. C. M. (2012). Avaliação do ler e do escrever em surdos pela Língua Brasileira de Sinais (Libras). Psicologia Teoria e Prática, 14(2), 15-27.

Quinteiro, R. de S. (2014). Aquisição de discriminações auditivo-táteis e emergência de leitura recombinativa em Braille (Tese de doutorado, Programa de Pós-graduação em Psicologia, Universidade Federal de São Carlos, SP, Brasil).

Resende, A. A. C., Elias, N. C., \& Goyos, C. (2012). Transferência de funções ordinais através de classes de estímulos equivalentes em surdos. Acta Comportamentalia, 20(3), 317-326.

Rosa, A. B., Filho, de Rose, J. C., de Souza, D. G., Hanna, E. S., \& Fonseca, M. L. (1998). Aprendendo a ler e a escrever em pequenos passos [Software para computador].

Santos, S. de L. R. (2012). Caracterização de desempenhos envolvidos na leitura e na escrita em crianças com deficiência auditiva (Dissertação de mestrado, Programa de Pós-graduação em Psicologia do Desenvolvimento e Aprendizagem, Universidade Estadual Paulista Júlio de Mesquita Filho, Bauru, SP, Brasil).

Schusterman, R. J., \& Kastak, D. (1993). A California see lion (Zlophus californianus) is capable of forming equivalence relations. The Psychological Record, 43, 823-839.

Sidman, M. (1977). Teaching some basic prerequisites for reading. In P. Mittler (Ed.), Research to practice in mental retardation: Vol. 2. Education and training (pp. 353-360). Baltimore, MD: University Park Press.

Sidman, M. (1994). Equivalence relations: $A$ research history. Boston, MA: Authors Cooperative.
Sidman, M., \& Tailby, W. (1982). Conditional discrimination vs. matching to sample: An expansion of the testing paradigm. Journal of the Experimental Analysis of Behavior, 37, 5-22.

Sidman, M., Wynne, C. K., Maguire, R. W., \& Barnes, T. (1989). Functional classes and equivalence relations. Journal of the Experimental Analysis of Behavior, 52(3), 261-174.

Souza, F. C., Almeida-Verdu, A. C. M., \& Bevilacqua, M. C. (2013). Ecoico e nomeação de figuras em crianças com deficiência auditiva pré-lingual com implante coclear. Acta Comportamentalia, 21(3), 325-339.

Stromer, R., Mackay, H. A., \& Stoddard, L. T. (1992). Classroom applications of stimulus equivalence technology. Journal of Behavioral Education, 2, 225-256.

Velasco, S. M., Huziwara, E. M., Machado, A., \& Tomanari, G. A. Y. (2010). Associative symmetry by pigeons after few-exemplar training. Journal of the Experimental Analysis of Behavior, 94(5), 283-295.

Wechsler, D., \& Figueiredo, V. L. M. (2002). WISC-III: Escala de Inteligência Wechsler para crianças. Adaptação brasileira da $3^{a}$ edição. São Paulo, SP: Casa do Psicólogo.

Zaine, I., Domeniconi, C., \& de Rose, J. C. (2014). Simple and conditional discrimination and specific reinforcement in teaching reading: An interventional package. The Analysis of Verbal Behavior, 30, 193-204.
Recebido: 15/05/2015

$1^{a}$ revisão: $29 / 10 / 2015$

$2^{a}$ revisão: $21 / 01 / 2016$

Aceite final: 21/02/2016 